\title{
A NOTE ON RICHTER-TYPE MAGNETIC RELAXATION IN FERRITES
}

K вопросу о магнитной релаксащии типа Рихтера у ферритов

Magnetic relaxation of the Richter type characterized by the relaxation time

$$
\tau=\tau_{\infty} e^{\varepsilon / k T}
$$

has recently been studied by Kienlin with nickel-zine ferrite [1] and by us for nonstoichiometric manganese ferrites [2]. In the first case the samples had the same ratio of cations but they had different values of the activation energy $\varepsilon$ in relation (1) as a result of the different firing temperature. In our paper the activation energy varied chiefly as a result of the different ratio of the ions of $\mathrm{Fe}$ and $\mathrm{Mn}$ and secondly also depended on

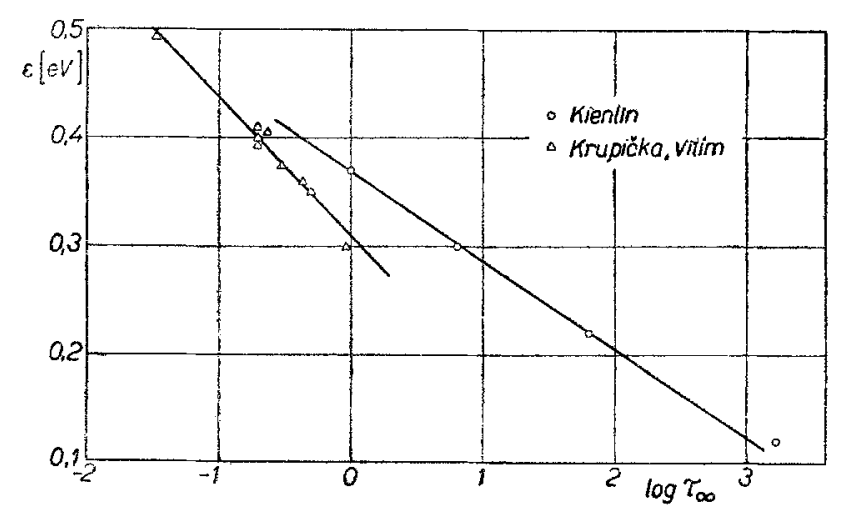

Fig. 1 .

the content of oxygen in the samples. In both papers it was found that the constant $\boldsymbol{\tau}_{\infty}$ is connected with the value of the activation energy $\varepsilon$ in that $\tau_{\infty}$ decreases with increasing $\varepsilon$.

The aim of this note is to point out that for a given type of samples this connection can be expressed by a simple linear relation

$$
\varepsilon=A \log \tau_{\infty}+B
$$

where the constants $A$ and $B$ are characteristic for the given type of material and given relaxation diffusion mechanism. These dependences are plotted in Fig. 1 for Kienlin's and our measurements.

Relation (2) is a complete analogy of the Meyer Neldel law for the electric conductivity of semi-conductors [3]; it suffices merely to replace $\tau_{\infty}$ by the constant $\sigma_{0}$ from the exponential law $\sigma=\sigma_{0} \theta^{-\varepsilon / k T}$. Here it should be noted that some time ago Brož [4] by measuring the electric conductivity of manganese zine ferrite with an excess of Fe ascertained the validity of this law for the case of changes in the activation energy caused by a different electric voltage on the sample.

Received 20.6. 1957.

Svatopluk KRUPiŏKa Institute of Technical Physics, Czechosl. Acad. Sci., Prague

\section{References - Jumepamypa}

[1] Kienlin A.: Zs. angew. Physik 9 (1957), 245.

[2] Krupiěka S., Vilím F.: Czechosl. Journ. Phys. \% (1957), 723.

[3] Meyer W., Neldel H.: Zs. techn. Physik 18 (1937), 588 .

[4] Brož J.: Czechosl. Journ. Phys. 6 (1956), 327. 